\title{
Role of Focus Strategy in Performance of NHIF Accredited Hospitals in Kenya
}

\author{
Grace K. A. Ochodo ${ }^{1}$, Margaret Oloko ${ }^{2} \&$ John Yabs $^{3}$ \\ ${ }^{1}$ Doctorate Student, Jomo Kenyatta University, Nairobi, Kenya \\ ${ }^{2}$ College of Human Resources Development, Jomo Kenyatta University, Nairobi, Kenya \\ ${ }^{3}$ School of Business UON, Eldoret Learning Centre, Eldoret, Kenya \\ Correspondence: Grace K. A. Ochodo, Doctorate Student, Jomo Kenyatta University, Nairobi, Kenya. E-mail: \\ gkochodo@gmail.com
}

Received: May 28, 2020

Accepted: June 22, 2020

Online Published: June 29, 2020

doi:10.5539/ijbm.v15n8p16

URL: https://doi.org/10.5539/ijbm.v15n8p16

\begin{abstract}
The mandate of the National Hospital Insurance Fund (NHIF) is to enable all Kenyans to access quality and affordable services. Consequently, NHIF accredited hospitals are positioned to facilitate the fulfilment of the said mandate, necessitating identification of competitive strategies employed by the hospitals for them to remain competitive. This study aimed at establishing the role of focus strategy on the performance of NHIF accredited hospitals within Kenya. A mixed research design was adopted based on non-experimental, descriptive and causal approaches taking into account both qualitative and quantitative techniques. The population of study comprised NHIF accredited hospitals with a bed capacity of 100 and above which stood at 150 hospitals as at July 2016. A sample of 109 hospitals was selected through stratified and convenient sampling techniques. Data was collected using semi structured questionnaires and interviewing schedules and administered to hospital administrators and CEO's respectively of the sampled hospitals. Quantitative data collected from the questionnaires was analysed by the help of SPSS while the qualitative data from the CEOs was analysed using thematic content analysis. The results of the study revealed that there is a positive and significant relationship between the focus study and performance of hospitals based on the regression coefficient estimate found to be $\beta=0.646$, P value of the coefficient estimate of the focus study which is less than 0.05 level of significance. The quantitative result was further validated by the CEOs responses that indicated that they focus on niche market that remained unexploited.
\end{abstract}

Keywords: competitive strategies, focus strategies, NHIF accredited hospitals, performance

\section{Introduction}

Significant number NHIF accredited hospitals in Kenya are today faced with dynamic and uncertain business environment. (Tromstedt \& Haapasalo, 2012) indicated that today's business environment is turbulent and characterized by uncertainty and inability to predict the future thus operating a business is extremely challenging, requiring the development and application of new knowledge and capacities that are needed to enhance performance. The competition in the market has rendered the success of any given NHIF accredited hospitals to be largely dependent on its strategic awareness. For the purpose of market survival, hospitals in Kenya must aim at competing effectively with the view to outperform their rivals in a competitive environment.

Firm competitiveness largely relies on the strategies that a company adopts to outperform its rivals in the market. such strategies include cost leadership strategy, differentiation strategy focus or niche strategy. The current study focusses on focus strategy. This comprises of production of goods aimed for a particular market segment to the exclusion of others (Lahtinen \& Toppinen, 2006). Hospitals that practice focus strategy focusing a given market select a category or classification of segments in the industry and tailor its strategy to serving them to the omission of others. By continuously honing its strategy for the target segments, the focuser strives to achieve a superior performance in its target segments even though it does not possess a competitive advantage overall. The focus strategy has two variants, cost focus and differentiation focus.

Cost focus exploits differences in cost behaviour in some segments, while differentiation focus exploits the special needs of buyers in certain segments (Porter, 1980). This strategy targets a narrow segment of a market 
not served well by cost leadership strategy and tailors its products to the needs of that specific segment to the exclusion of others (Johnson, 2011). It is also employed when it is not appropriate to apply the broad cost leadership (Porter, 1985), by offering a limited range of services/products, serving specific markets only or having special product/service for specific type of customers (Allen \& Helms, 2006; Hahn \& Powers, 2010). Therefore, performance of NHIF accredited hospitals in Kenya can be a good pointer of the outcome of the competitive strategies specifically focus strategy identified for use in this study. The aim of competitive strategies is to cope with and change industry rules in the firm's favour. Competition in service delivery, for the hospital industry in Kenya requires identification of competitive strategies employed in order for them to remain competitive.

Focus strategy directs its efforts to a particular market segment. This means attending to a segment more efficiently and effectively than the competitors. The strategy can be employed in a dual application of cost leadership or differentiation strategy aimed towards a narrow, focused market. Benefits associated with focus strategy include having power over buyers since the firm may be the only source of supply. Customer loyalty also protects the firm from new entrants and substitute products.

The firm adopting focus strategy can easily stay close to customers and monitor their needs. However, the disadvantages involved in focus strategy include being at the mercies of powerful suppliers since such a firm will buy in smaller quantities. Small volume also means higher production cost leading to loss of economies of scale. In addition, change in consumer taste or a technological change could cause such a firm's niche to disappear. Cost leaders, or larger firms may also gain interest in a particular niche, eroding the advantage of the focusing firm. The focus strategy achieves either cost advantage or differentiation within a narrow concentration.

A firm using a focus strategy often enjoys a high level of customer trustworthiness, and this entrenched loyalty discourages other firms from competing directly. Organizations pursuing focus strategy tend to have narrow market niche, and hence lower volumes leading to low bargaining power with their suppliers. However, business adopting the differentiation focused strategy may be able to pass the premium cost on to customers since close substitute products do not exist. Some risks of focus strategies include simulation and changes in the target segments (Pearce \& Robinson, 2008). According to (Porter, 2004), performance is the most imperative goal and the main determinant of productivity but essential and calculates performance and its basis has been debatable among researchers and scholars. Accordingly, competition in health service delivery amongst hospitals in Kenya and the challenges they were facing such as cost of maintaining quality, economic recession, cost of maintaining skilled staff, and unpredictable government policies should motivate NHIF accredited hospitals in Kenya to seek and adopt competitive strategies to enable them compete favourably. Notwithstanding the many studies that have been carried out about competitive strategies in Kenya, there is a gap on how the adoption of focus strategy by hospitals can influence performance especially in NHIF accredited hospitals in Kenya. With the foregoing, this study was undertaken to assess the effect of focus strategy on the performance of NHIF accredited hospitals in Kenya.

\section{Statement of the Problem}

Health systems around the world are faced with challenges of delivering access to quality and affordable health services to its expansive populations. Hospitals compete on service quality, process execution and service diversification (Rivers \& Clovers, 2010). Competition generally eliminates inefficiencies that may lead to high costs of operation. The merits of competition argument in favor of competition is that it can be designed and employed to create formidable inducements that motivate providers to innovate so to deliver high quality goods and services at lower costs. Strategies employed by firms in their operations vary widely depending on the operating environment. Cotemporally, operational set up of Kenya's health sector is dynamic and highly competitive in the wake of the emergence of many private hospitals. Public hospitals following generic strategies may realize a performance advantage over competitors that pursue other strategy type or those that are stuck in the middle (Karanja, 2012).

Previous studies have endeavored to investigate the effects of competitive strategies adopted by other industries on performance: A small number of studies in Kenya have examined the health sector in general such as (Varma, 2013) studied the 'Competitive strategies' adopted by Aga Khan University Hospital in Nairobi, but not specifically on the NHIF accredited hospitals in Kenya. Therefore, no study has been carried out in the Country so far to specifically determine the effect of focus strategy on the performance of NHIF accredited hospitals in Kenya. This study therefore, sought to address the gap.

\section{Objective of the Study}

The objective of the study was to explore the effect of focus strategy on the performance of NHIF accredited 
hospitals in Kenya.

\subsection{Hypothesis}

$\mathrm{H}_{01}$ : There is no significant effect of focus strategy on the performance of NHIF accredited hospitals in Kenya.

\section{Literature Review}

\subsection{Strategic Contingency Theory and Generic Business Strategies}

Strategic contingency theory has its origins in the structure-strategy-performance paradigm associated with institutional economists though focuses less on structure and more on strategy. The theory focuses on matching strategy to environment. Notwithstanding that. many theorists have explored the relationship between environment and strategy, much of the early work was completed by Porter. According to (Porter, 1980), the intrinsic nature of formulating competitive strategy is relating a company to its environment. Porter developed generic strategies namely cost leadership, differentiation, and focus. These strategies are a result of various environmental features but are anchored in the firm's decision to pursue a broad or narrow target market and a uniqueness or cost competency. (1980, p. 41) states that, "the firm failing to develop its strategy in at least one of the three directions (a firm that is "stuck in the middle") is in an extremely poor strategic situation." This "stuck-in-the-middle" scenario is discussed by (Porter, 1980) on a global level with the use of example firms that compete in multiple foreign markets. Porter's rigid view of the appropriateness of utilizing one generic strategy and one only, regardless of environmental conditions, has been criticized (Hill, 1988). However, there is some empirical evidence that a hybrid approach may be usefully applied (Hlavacka et al., 2001).

\subsection{Porter's Generic Business Strategies}

According to Porter, as cited by (Davidson, 2001), the companies must be competitive in order to become an industry leader and be successful both nationally and abroad. These strategies according to (Hahn Powers, 2010) that support gaining competitive advantage apply to all industries in most nations).

\subsection{Focus Strategy}

Focus strategy singles out a narrow competitive scope within an industry. The focuser identifies a segment or group of segments in the industry and aligns its strategy to serving them to the exclusion of others. Focus strategy is presented, as Low-Cost focused strategy and Focused Differentiation strategy.

\section{4 Focused Low-Cost Strategy}

The focused low-cost strategy is directed to those clients who desire to consume products at a low cost, and the company that pursues this strategy competes against the cost leader in the niche market where it has a cost advantage.

With this strategy, a company concentrates on small volume cost-built product for which it has cost advantage. The company may adapt this strategy to save a buyer segment whose needs can be satisfied with less costs compared to the rest of the market.

\subsection{Focused Differentiation Strategy}

Focused differentiation strategy is the strategy to operating a business with a differentiated product in a chosen niche market. When a firm pursues a focused strategy based on differentiation, it concentrates on a narrow buyer segment and offers customized in products better than competing products.

The focuser, firm competes against competitors not based on low-cost rather based on product differentiation. Since the focuser company knows the needs of niche customer groups it can successfully differentiate its product.

Focused differentiation strategy provides unique attributes to attract different customers. However, there is a need to satisfy a narrow segment of a market. Focused differentiation strategy provides unique factors that fulfill the demands of a narrow segment of market. Some firms using this focused strategy use their efforts on a particular niche such as specific demographic segment such as the senior citizens in a community.

The differentiation strategy involves providing unique features to attract a variety of customers, however there is a need to satisfy a narrow market segment. Some firms using focused differentiation strategy use their marketing efforts to target a sales channel such as specific demographic niches.

In the focus strategy, a firm targets a specific segment of the market. The firm can choose to concentrate on a select customer group, product range, geographical area, or service line. Focus is also based on adopting a narrow competitive scope within an industry. It aims at growing market share through operating in a niche 
market or in markets either not attractive to, or overlooked by, larger competitors. These niches arise from a number of factors including geography, buyer characteristics, and product specifications or requirements. A successful focus strategy (Porter, 1980) depends upon an industry segment large enough to have good growth potential but not of key importance to other major competitors. Market penetration or market development can be an important focus strategy. Medium sized and large firms use focus-based strategies but only in conjunction with others generic strategies. But, focus strategies are most effective when consumers have distinct preferences and when the niche has not been pursued by rival firms (David, 2000).

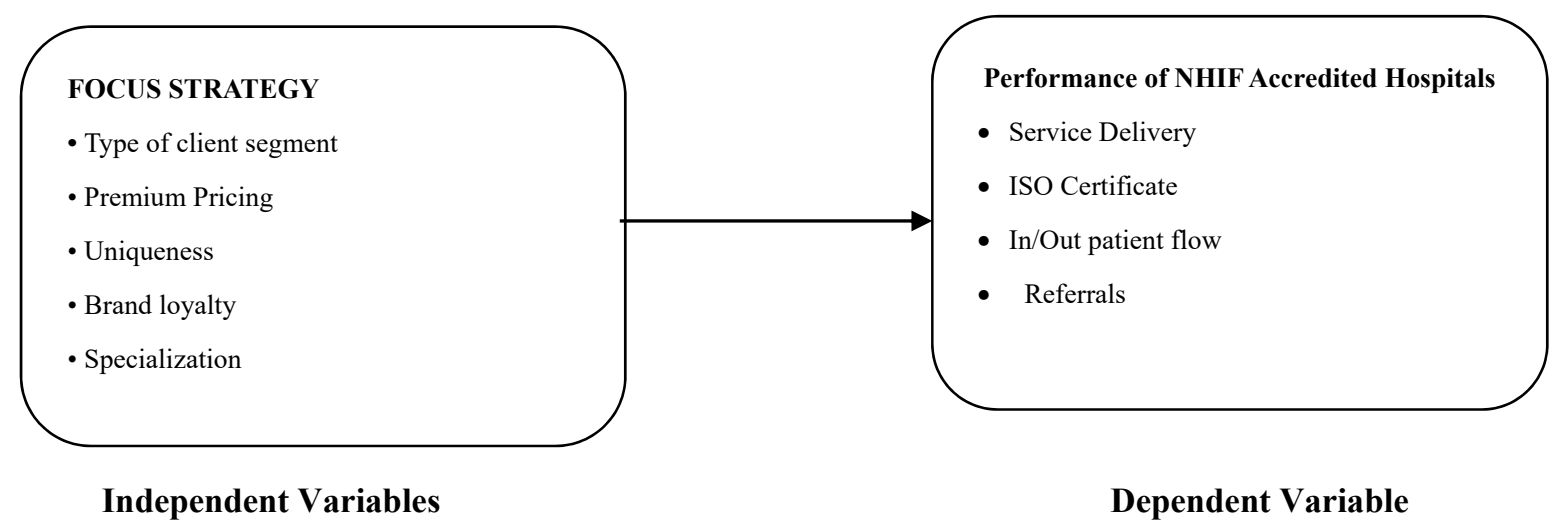

Figure 1. Conceptual framework

\subsection{Organizational Performance}

Organizational performance may be measured using financial and non-financial success measures at various levels including company, industry and product. Most studies on organizational performance use a variety of financial and non-financial success measures. Researchers employ financial measures such as profit, turnover, return on investment, return on capital employed, non-financial measures include innovativeness, in service delivery and process execution especially in respect to the health sector Measures of firm performance generally include bottom-line financial indicators such as sales, profits, cash flow, return on equity, and growth. It is however, also important to determine how a firm compares with its industry competitors when assessing firm performance (Dess \& Robinson, 1984). With the multitude of competitive environments face body firms in different industries, knowing only absolute financial numbers such as sales, profits, or cash flow is not very illuminating unless viewed in the context of how well the firm is doing compared to their competition.

\section{Research Methodology}

This study utilized a cross -sectional survey design based on a sample drawn from NHIF accredited hospitals in Kenya that cut across various Counties. Descriptive research design was chosen because it is efficient in collecting large amounts of information within a short time. The general population of this study was NHIF accredited hospitals in Kenya with a bed capacity of 100 and above which stood at 150 hospitals as at July 2016. The instruments used to collect data for the study were semi-structured questionnaires and interview schedules. The data from the completed questionnaires was cleaned, coded and entered into the computer for analysis using the Statistical Package for Social Sciences. Qualitative and quantitative analysis approaches were adopted using Descriptive statistics to describe the existing status of the hospitals with respect to the variables studied. To assess the effect of focus strategy on the performance of hospitals, regression models were fitted. Simple linear regression based on Ordinary least squares was employed to assess the direct effect of $t$ focus strategy on performance of hospitals. The significance of the influence by the independent variables was based on the t-tests of the estimated coefficient estimates of the independent variable in the model.

\section{Results and Discussion of Research Findings}

In order to explore the relationship between focus strategy and the performance of NHIF accredited hospitals in Kenya, the Statistical Package for Social Sciences (SPSS version 21) windows were used to derive for the descriptive statistics. The analysis and interpretation of the findings was in relation to the study purpose of the study. 


\subsection{Descriptive Analysis of the Performance of NHIF Accredited Hospitals in Kenya}

Performance was the dependent variable of the study which was measured by 5 indicators of which 4 were retained following construct validity assessment carried out on the pilot study. The indicators were measured on an ordinal Likert scale of 5 as categorical representations of the levels of agreement by the respondents on the indicator statements from strong disagreement to strong agreement. In table 1, are the descriptive statistics of the data on each indicator of performance. The first indicator of the construct of performance sought to find out the view of the respondents regarding whether the hospital has an average of $50 \%$ bed occupation at any time. Majority (46.9\%) of the respondents agreed. There were $0 \%$ respondents who strongly disagreed, while $8.6 \%$ of the respondents disagreed and $12.4 \%$ of the respondents were neutral. Some $46.9 \%$ of the respondents agreed and another $32.1 \%$ strongly agreed that the hospital has an average of $50 \%$ bed occupation at any time.

As per the indicator that the hospital has high rate of in/out patient flow due to outstanding service delivery, the distribution was that there were $0 \%$ respondents who strongly disagreed, while $1.2 \%$ of the respondents disagreed and $6.2 \%$ of the respondents were neutral. Some $54.3 \%$ of the respondents agreed and another $38.3 \%$ strongly agreed that the hospital has high rate of in/out patient flow due to outstanding service delivery.

Majority (34.6\%) of the respondents agreed that the hospital receives an average of 50 referrals per day. There were $6.2 \%$ respondents who strongly disagreed, while $21 \%$ of the respondents disagreed and $21 \%$ of the respondents were neutral. Some $34.6 \%$ of the respondents agreed and another $17.3 \%$ strongly agreed that the hospital receives an average of 50 referrals per day.

The fourth indicator of the variable sought to find out the view of the respondents regarding whether the hospital is a frequent recipient of service accreditation awards. Majority (37\%) of the respondents agreed. There were $2.5 \%$ respondents who strongly disagreed, while $7.4 \%$ of the respondents disagreed and $21 \%$ of the respondents were neutral. Some $37 \%$ of the respondents agreed and another $32.1 \%$ strongly agreed that the hospital is a frequent recipient of service accreditation awards. As per the indicator that the average outpatient treatment turnaround time is less than three hours, the distribution was that there were $1.2 \%$ respondents who strongly disagreed, while $3.7 \%$ of the respondents disagreed and $16.1 \%$ of the respondents were neutral. Some $22.2 \%$ of the respondents agreed and another $56.8 \%$ strongly agreed that the average outpatient treatment turnaround time is less than three hours.

Table 1. Performance of hospitals in Kenya

\begin{tabular}{|c|c|c|c|c|c|c|c|c|}
\hline & & 1-SD & 2-D & $3-\mathrm{N}$ & 4-A & 5-SA & Mean & $\begin{array}{l}\text { Std } \\
\text { dev. }\end{array}$ \\
\hline \multirow{2}{*}{$\begin{array}{l}\text { The hospital has an average of } 50 \% \text { bed } \\
\text { occupation at any time }\end{array}$} & Freq. & 0.00 & 7.00 & 10.00 & 38.00 & 26.00 & \multirow[t]{2}{*}{4.025} & \multirow[t]{2}{*}{0.894} \\
\hline & Percent & 0.00 & 8.64 & 12.35 & 46.91 & 32.10 & & \\
\hline \multirow{2}{*}{$\begin{array}{l}\text { The hospital has high rate of in/out patient } \\
\text { flow due to outstanding service delivery }\end{array}$} & Freq. & 0.00 & 1.00 & 5.00 & 44.00 & 31.00 & \multirow[t]{2}{*}{4.296} & \multirow[t]{2}{*}{0.641} \\
\hline & Percent & 0.00 & 1.23 & 6.17 & 54.32 & 38.27 & & \\
\hline \multirow{2}{*}{$\begin{array}{l}\text { The hospital receives an average of } 50 \\
\text { referrals per day }\end{array}$} & Freq. & 5.00 & 17.00 & 17.00 & 28.00 & 14.00 & \multirow[t]{2}{*}{3.358} & \multirow[t]{2}{*}{1.176} \\
\hline & Percent & 6.17 & 20.99 & 20.99 & 34.57 & 17.28 & & \\
\hline \multirow{2}{*}{$\begin{array}{l}\text { The hospital is a frequent recipient of } \\
\text { service accreditation awards }\end{array}$} & Freq. & 2.00 & 6.00 & 17.00 & 30.00 & 26.00 & \multirow[t]{2}{*}{3.889} & \multirow[t]{2}{*}{1.025} \\
\hline & Percent & 2.47 & 7.41 & 20.99 & 37.04 & 32.10 & & \\
\hline \multirow{2}{*}{$\begin{array}{l}\text { The average outpatient treatment } \\
\text { turnaround time is less than three hours }\end{array}$} & Freq. & 1.00 & 3.00 & 13.00 & 18.00 & 46.00 & \multirow[t]{2}{*}{4.296} & \multirow[t]{2}{*}{0.955} \\
\hline & Percent & 1.23 & 3.70 & 16.05 & 22.22 & 56.79 & & \\
\hline
\end{tabular}

Source: Fields Survey.

The different indicators of performance were generally noted not to vary across the 3 classifications. Cross tabulations of each indicator and hospital classifications was used as the assessment of the association between them and performance (Table 2). Chi-square tests of association was carried out for each contingency table and also presented in the table. The tests showed that all the indicators of performance had no significant association with the differences in classifications of the hospitals except the question on whether the hospital has an average of $50 \%$ bed occupation at any time. The chi-square statistics from all the contingency tables showed had p-values greater than 0.05 implying insignificant association between the indicator and classifications. The p-value of the of the indicator Bv1 however had a p-value of 0.023 which is less than 0.05 implying that the 
levels bed occupation at any given time vary across hospitals differently based on the classification of the hospital.

\subsection{Descriptive Analysis of the Focus Strategy in NHIF Accredited Hospitals}

The measurement of Focus strategy was based on 5 indicators that were all considered valid and reliable and thus retained during the pilot study. The indicators were also measured on an ordinal Likert scale of 5 as categorical representations of the levels of agreement by the respondents on the indicator statements from strong disagreement to strong agreement. In table 2, are the descriptive statistics of the data on each indicator of performance.

The first indicator of the construct sought to find out the view of the respondents regarding whether the hospital has put in place facilities to treat different health conditions. Majority (58\%) of the respondents agreed. There were $0 \%$ respondents who strongly disagreed, while $1.2 \%$ of the respondents disagreed and $0 \%$ of the respondents were neutral. Some $58 \%$ of the respondents agreed and another $40.7 \%$ strongly agreed that the hospital has put in place facilities to treat different health conditions.

As per the indicator that the hospital has a reputation for handling non-communicable diseases, the distribution was that there were $0 \%$ respondents who strongly disagreed, while $2.5 \%$ of the respondents disagreed and $3.7 \%$ of the respondents were neutral. Some $46.9 \%$ of the respondents agreed and another $46.9 \%$ strongly agreed that the hospital has a reputation for handling non-communicable diseases.

The third indicator of the variable sought to find out the view of the respondents regarding whether the facility is a referral institution for the diplomatic fraternity within the East African region. Majority (40.7\%) of the respondents agreed. There were $4.9 \%$ respondents who strongly disagreed, while $7.4 \%$ of the respondents disagreed and $29.6 \%$ of the respondents were neutral. Some $40.7 \%$ of the respondents agreed and another $17.3 \%$ strongly agreed that the facility is a referral institution for the diplomatic fraternity within the East African region.

The fourth indicator of the variable sought to find out the view of the respondents regarding whether the hospital focuses on children. Majority (49.4\%) of the respondents agreed. There were $1.2 \%$ respondents who strongly disagreed, while $6.2 \%$ of the respondents disagreed and $12.4 \%$ of the respondents were neutral. Some $49.4 \%$ of the respondents agreed and another $30.9 \%$ strongly agreed that the hospital focuses on children.

The other indicator of the variable sought to find out the view of the respondents regarding whether the pricing structure is attractive to the clientele segment. Majority (49.4\%) of the respondents agreed. There were $2.5 \%$ respondents who strongly disagreed, while $0 \%$ of the respondents disagreed and $6.2 \%$ of the respondents were neutral. Some $49.4 \%$ of the respondents agreed and another $42 \%$ strongly agreed that the pricing structure is attractive to the clientele segment.

Table 2. Descriptive statistics for focus strategies

\begin{tabular}{|c|c|c|c|c|c|c|c|c|}
\hline & & 1-SD & 2-D & $3-N$ & 4-A & 5-SA & Mean & Std dev. \\
\hline \multirow{2}{*}{$\begin{array}{l}\text { The hospital has put in place facilities to } \\
\text { treat different health conditions. }\end{array}$} & Freq. & 0.00 & 1.00 & 0.00 & 47.00 & 33.00 & \multirow[t]{2}{*}{4.383} & \multirow[t]{2}{*}{0.681} \\
\hline & Percent & 0.00 & 1.23 & 0.00 & 58.02 & 40.74 & & \\
\hline \multirow{2}{*}{$\begin{array}{l}\text { The hospital has a reputation for handling } \\
\text { non-communicable diseases. }\end{array}$} & Freq. & 0.00 & 2.00 & 3.00 & 38.00 & 38.00 & \multirow[t]{2}{*}{3.580} & \multirow[t]{2}{*}{1.023} \\
\hline & Percent & 0.00 & 2.47 & 3.70 & 46.91 & 46.91 & & \\
\hline \multirow{2}{*}{$\begin{array}{l}\text { The facility is a referral institution for the } \\
\text { diplomatic fraternity within the East African } \\
\text { region. }\end{array}$} & Freq. & 4.00 & 6.00 & 24.00 & 33.00 & 14.00 & \multirow[t]{2}{*}{4.025} & \multirow[t]{2}{*}{0.894} \\
\hline & Percent & 4.94 & 7.41 & 29.63 & 40.74 & 17.28 & & \\
\hline \multirow{2}{*}{ The hospital focuses on children. } & Freq. & 1.00 & 5.00 & 10.00 & 40.00 & 25.00 & \multirow[t]{2}{*}{4.284} & \multirow[t]{2}{*}{0.794} \\
\hline & Percent & 1.23 & 6.17 & 12.35 & 49.38 & 30.86 & & \\
\hline \multirow{2}{*}{$\begin{array}{l}\text { The pricing structure is attractive to the } \\
\text { clientele segment. }\end{array}$} & Freq. & 2.00 & 0.00 & 5.00 & 40.00 & 34.00 & \multirow[t]{2}{*}{4.037} & \multirow[t]{2}{*}{0.901} \\
\hline & Percent & 2.47 & 0.00 & 6.17 & 49.38 & 41.98 & & \\
\hline
\end{tabular}

Sources: Fields Survey.

\subsection{The Relationship between Focus Strategy and the Performance of NHIF Accredited Hospitals in Kenya}

The purpose of the study was to determine the relationship between Focus strategy as an independent variable 
with the performance of NHIF accredited Hospitals in Kenya. Factor analysis was carried out for dimension reduction of to generate latent constructs for further inferential analysis and further assess the relationship between focus strategy and performance. The indicators for each variable were reduced into one factor to generate the factor scores of the variable using Confirmatory factor analysis (CFA) to restrict the indicators hypothesized to belong to one variable to one factor model. The CFA results were used further used to assess the construct validity of the indicators of each of the 2 constructs to measure the 2 variables. This was done achieved by assessing the sampling adequacy for each CFA model using KMO and Bartlett's statistics, assessing the factor loadings of each indicator on the variables which was achieved and expunging indicators that did not adequately load the latent constructs and finally assessing for convergent validity basing on the Average variances extracted (AVEs) and the squared correlations (Kline, 2011). A summary generated from the CFA results in in table 3 shows KMO values above 0.5 and Bartlett's statistics have p-values of 0.000 which are less than 0.05 which implies sampling adequacy and suitability of the data for factor analysis to generate the latent variables of cost leadership strategy and performance (Laura J. Burton \& Stephanie M. Mazerolle, 2011). One indicator did not have adequate factor loadings above 0.4 on performance and was thus expunged retaining items (indicators) of performance and all the items of focus strategy that was adequately loaded by all items in the CFA model. The retained items however exhibited both convergent and discriminant validity as shown by the AVEs that are greater than the corresponding squared correlations and also greater than 0.5 (Kline, 2011). The 2 latent variables generated were therefore considered to exhibit adequate construct validity and were used in further analysis to assess for inter-relationships between the constructs.

Table 3. Correlation between cost leadership strategy and performance

\begin{tabular}{lllllll}
\hline & AVE & $\begin{array}{l}\text { Squared } \\
\text { correlations }\end{array}$ & $\begin{array}{l}\text { Retained } \\
\text { Items }\end{array}$ & KMO & $\begin{array}{l}\text { Bartlett's } \\
\text { Chi Square }\end{array}$ & P-value \\
\hline Focus strategy & 0.667 & 0.515 & 6 out of 6 & 0.745 & Chi2(15) $=61.981$ & 0.000 \\
Performance & 0.805 & 0.594 & 4 out of 5 & 0.772 & Chi2(6) $=62.224$ & 0.000 \\
\hline
\end{tabular}

Source: Fields Survey.

To assess the direct effect of focus strategy as a predictor of performance of major hospitals in Kenya, a simple bivariate linear regression model between the 2 constructs was fitted to estimate the significance and magnitude of the linear influence (coefficient) of focus strategy. Considering the use of Ordinary Least Squares (OLS) in fitting the model, the classical assumptions (normality, homoscedasticity and non-autocorrelation) of linear modeling was therefore tested on the model residuals as detailed in Table 6.

To confirm normality of the residuals, a test for normality using Shapiro-Wilk test was carried out. As shown in table 4, the p-value of the Shapiro-Wilk statistic was found to be greater than 0.05 to imply that the distribution of the model residuals does not significantly deviate from normality. Homoscedasticity of the residuals as a classical assumption of OLS was also assessed. The Breusch-Pagan test for homogeneity of variance was carried out where the BP Lagrange Multiplier (LM) statistic was computed for the residuals. The P-value of the BP-LM Chi-square statistic was found to be 0.067 which is greater than 0.05 . This showed that that the model residuals did not exhibit heteroscedasticity but were homoscedastic implying that the model met the homoscedasticity assumption.

The linear model assumption of autocorrelation was also tested on the residuals of the model used to assess the effect of focus strategy on performance. Autocorrelation also referred to as serial correlation is the phenomenon where observations of a variable (residuals) are a function of other successive values of the same variable. Autocorrelation of the model residuals implies that successive values of the residuals can be sued to predict other values of the residual term. The Durbin-Watson (d) test was used to check for existence of autocorrelation of the residuals. Small values of the D-W statistic indicated successive error terms were correlated. As shown in the results, the calculated D-W statistic is larger than the upper tabulated value (1.662) from Durbin-Watson tables shown in appendix VIII. The tabulated upper value for a model with one regressor and a sample size of 81 is less than the calculated D-W which is an indication that the residuals are not serially related thus the non-autocorrelation assumption is met. 
Table 4. Diagnostic tests; focus strategy and performance model

\begin{tabular}{lllll}
\hline & Test & Statistic & P-value & Conclusion \\
\hline Normality & Kolmogorov-Smirnov & 0.049 & .200 & Normally distributed residuals \\
& Shapiro-Wilk & 0.991 & 0.869 & Normally distributed residuals \\
Homoscedasticity & BP-LM & 2.929 & 0.087 & Homoscedastic residuals \\
Autocorrelation & Durbin-Watson & 1.869 & & Non- auto-correlated residuals \\
\hline
\end{tabular}

Source: Fields Survey.

The diagnostic tests confirmed that the model fitted between focus strategy and performance met all the linear modelling assumptions. The model summary Table 5 provides information regarding the ability of the regression line to predict the variation in the dependent variable. The coefficient of determination (R-square) also referred to as the explanatory power of this model was found to be 0.411 . This is shows that $41.1 \%$ of the variation in performance of the hospitals is explained by the variation of predictors in the model (focus strategy). The difference Percentage, $58.9 \%$ is the portion of variance explained by other factors that have not been included in this model that only considered focus strategy.

Table 5. Model Summary; focus strategy and performance model

\begin{tabular}{llll}
\hline $\mathrm{R}$ & $\mathrm{R}$ Square & Adjusted R Square & Std. Error of the Estimate \\
\hline $.641^{\mathrm{a}}$ & .411 & .404 & $\mathbf{. 7 6 8 7 8 4 8 7}$ \\
\hline
\end{tabular}

a. Predictors: (Constant), X2; b. Dependent Variable: Y.

Source: Fields Survey.

From the ANOVA table 6, the P-value of the F-statistic is less than 0.05 showing that the coefficient estimates of the model are jointly not equal to zero. This implies that the model is statistically significant in predicting focus strategy impacts the performance of hospitals in Kenya. The results show that the proportion of variance of performance that is due to the regression predictor (focus strategy) is significantly explained in the model. The table shows the proportion of the total variance of the dependent variable that is apportioned to the variation that can be explained by the predictors in the model and the remaining variance due to the residuals that cannot be explained by the independent variables in the model.

Table 6. ANOVA; focus strategy and performance model

\begin{tabular}{llllll}
\hline & Sum of Squares & df & Mean Square & F & Sig. \\
\hline Regression & 32.581 & 1 & 32.581 & $.000^{\mathrm{b}}$ \\
Residual & 46.691 & 79 & .591 & \\
Total & 79.272 & 80 & & \\
\hline
\end{tabular}

a. Dependent Variable: Y; b. Predictors: (Constant), X3.

Source: Fields Survey.

The regression coefficient estimate of the influence of focus strategy on performance is detailed in table 9. The results show that focus strategy has a significant coefficient estimate $(\beta=0.646, \mathrm{t}=7.425$, $\mathrm{p}$-value $=0.000)$ as a predictor of performance of hospitals in Kenya. The p-value of the coefficient is less than 0.05 implying significance at $5 \%$ level of significance. The results show that increasing the levels of focus strategy by one unit would result in an increase in performance of the hospitals by 0.646 units. The model fitted generated the following; equation:

$$
\mathrm{Y}=0.646 \mathrm{X}+\varepsilon
$$


Table 7. Coefficients: focus strategy and performance model

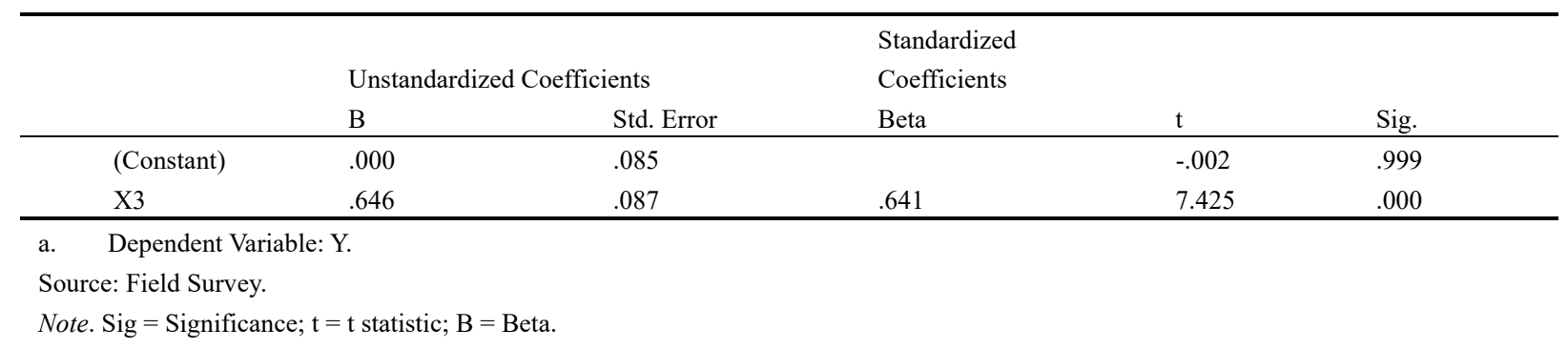

$\mathrm{H}_{01}$ : There is no significant effect of Focus strategy on the performance of NHIF accredited hospitals in Kenya.

According to the results, the p-value of the coefficient of Focus strategy was found to be 0.000 which is less than the 0.05 level of significance threshold. The null hypothesis was therefore rejected and a conclusion drawn that Focus strategy has a significant relationship with the performance of NHIF accredited hospitals in Kenya. The results show that Focus strategy has a significant impact on performance therefore hospital administrators should consider improving on Focus strategies to realize improved performance.

The results from the interviews carried out also concur with the findings of the quantitative analysis regarding this objective. Through focus strategy, the hospitals tend to have ability to achieve performance though retaining the clients and the maintaining the market share of the hospital. Some of the CEOs manage the hospitals through focus strategies by focusing on niche markets that have not been explored in their localities. On the question of the strategies used, one of the CEOs adopting focus strategies said that: "The most common business strategy we use here is focusing on the niche market, we mostly focus on the children, and the hospital is clean always to enhance health".

Another CEOs response to the strategies used and its influence on performance was on the use of both cost leadership strategies and focus strategies: "Cost leadership and focus strategy majors on maternity and children we have equipment theatre needed/strategy the art of technology impressive costumes flow etc. our focus being on maternity and children most of the clients tend to be attracted to the facility and due to our quality and affordable costs it increases our market share in the hospital industry."

\section{Conclusions}

The study generally sought to determine the relationship between the focus strategy and the performance of NHIF accredited hospitals in Kenya. The data were analyzed based the objective of the study. The direct effect of the relationship was measured by the regression coefficient estimate found to be $\beta=0.646$, indicating a positive relationship where increasing levels of focus strategy lead to increasing levels in performance of hospitals The null hypothesis of the study stated, 'that there is no significant effect of Focus strategy on the performance of NHIF accredited hospitals in Kenya'. The p-value of the coefficient estimate of focus strategy strategies on performance was less than the 0.05 level of significance thus the hypothesis rejected and a conclusion drawn that there is a significant relationship between Focus strategy and performance of NHIF accredited hospitals in Kenya. The effect of focus strategy was found to be positive and significant implying that increasing the levels of focus strategy strategies lead to an increase in the performance levels of the NHIF accredited hospitals in Kenya. It is instructive that the findings of the quantitative data analysis were validated by the findings of the qualitative analysis where the CEO's of the hospitals under study intimated that using focus strategy has resulted in improved financial and quality performance leading to increase in market share through increased patronage. The most niches were those of children and maternity services.

\section{Recommendations}

Based on the findings, analysis, discussions and conclusions of a study, the following recommendations are advanced: That NHIF accredited hospitals adopt focus strategy which has significant influence on the competitiveness of hospital facility. By employing Focus Strategy, the hospitals are able to offer services to consumers with differing needs and tastes including those requiring unique services at a low-cost; targeting specific niches like the aged; consumers with distinct preferences; with a view to reach out to a large consumer base and secure an increased market share.

It is also recommended that the NHIF encourage its accredited hospitals to adopt the focus strategy with a view to ensuring that it will facilitate the effective delivery of its mandate which is to ensure that all Kenyans access affordable and quality health services. 


\section{References}

Allen, S., \& Helms, M. (2006). Linking strategic practices and organizational performance to Porter's generic strategies. Business Process Management Journal, $12, \quad$ 433-436. https://doi.org/10.1108/09555349510147444

Clover, R. (2010). Healthcare competition; strategic mission and patient satisfaction. PHC, US National Library of Medical and Natural Institute of Health.

David, F. (2000). Strategic Management, Columbus: Merrill Publishing Company.

Hahn, W., \& Powers. T L. (2010). Strategic plan quality, implementation capability, and firm performance. Academy of Strategic Management Journal, 9(1), 63-81.

Hlavacka, H. T., Dicken, P., Forsgren, M., \& Malmberg, A. (2001). The local embeddedness of transnational corporations. In Amin, A., \& Thrift, N. (Eds.), Globalization, institutions and regional development in Europe. Oxford: Oxford University Press.

Johnson, G., Scholes, K., \& Whittington, R. (2011). Exploring Corporate Strategy: Text and cases (8th ed.). London, prentice Hall, Pearson education Ltd.

Karanja, P. W. (2012). Competitive strategies of real estate firms: The perspective of Porter's competitive advantage. Unpublished MBA Thesis. Nairobi: University of Nairobi.

Lahtinen, K., \& Toppinen, A. (2006). Financial performance in Finnish large-and medium sized sawmills: The effects of value-added creation and cost-efficiency seeking. Journal of Forest Economics.

McCracken, L. (2002). Differentiation: win new business with less effort. Principal's Report.

Mudaki, A. (2011). The Effect of Risk Underwriting Performance of Insurance Firms in Kenya. Unpublished MSC (HRM), Masinde Thesis Muliro University of Science and Technology.

Mwangi, E. M., \& Ombui, K. (2013). International Journal of Science and Research, 2.

Pearce, J. A., \& Robinson, R. B. (2008). Formulation, Implementation and Control of Competitive Strategy (9th ed.). Boston, MA: McGraw-Hill. Irwin.

Penelope, M. D., \& Meredith, D. (2010). When and How Provider Competition Can Improve Health Care Delivery. McKinsey \& Company.

Porter, M. (1986). Response to letters to the editor. Harvard Business Review, 2(2), 162-163. https://doi.org/10.1177/136346158602300216

Porter, M. (1987). Response to letters to the editor. Harvard Business Review, 2(2), 162- 163.

Porter, M. (2000). Competitive Advantage. Free Press.

Porter, M. (2008). Competitive Strategy: Techniques for analyzing industries and competitors. New York: Free Press.

Porter, M. E. (1985). Competitive Advantage: Creating and Sustaining Superior Performance. New York, NY.: Free Press.

Porter, M. E. (1996). Competitive Advantage: Creating and Sustaining Superior Performance. New York: Free Press.

Rój, J. (2016). Competition measurement of hospitals in Poland: the Herfindahl-Hirschman index approach. Ekonomika, 95(1), 166-181. https://doi.org/10.15388/Ekon.2016.1.9912

Stock, C. W. (1999). Strategic Management: A new view of Business policy and planning, little Brown \& company.

Stone, M. (1995). Strategic development related to Europeanization of UK logistics and distribution service suppliers. European Business Review, 95(5), 9-14. https://doi.org/10.1108/09555349510147444

Varmah, B. M. (2013). Competitive strategies adopted by Aga Khan University Hospital in Nairobi, Kenya and Challenges faced in their implementation. Unpublished MBA Thesis, University of Nairobi Private Sector Firms in Kenya.

\section{Copyrights}

Copyright for this article is retained by the author(s), with first publication rights granted to the journal.

This is an open-access article distributed under the terms and conditions of the Creative Commons Attribution license (http://creativecommons.org/licenses/by/4.0/). 